\title{
THE ACUTE CALCIFICATION OF TRAUMATIZED MUSCLE, WITH PARTICULAR REFERENCE TO ACUTE POST-TRAUMATIC RENAL INSUFFICIENCY ${ }^{1}$
}

\author{
By WILLIAM H. MERONEY, GLEN K. ARNEY, WILLIAM E. SEGAR, AND \\ HENRY H. BALCH \\ (From the Department of Metabolism, Division of Medicine, Walter Reed Army Institute of \\ Research, Walter Reed Army Medical Center, Washington 12, D. C.)
}

(Submitted for publication August 16, 1956; accepted February 25, 1957)

Previous studies of acute post-traumatic renal insufficiency in man have shown that plasma concentrations of inorganic phosphate and calcium were inversely related (2), and that those patients with extensive devitalization of muscle had the most acute and extreme hyperphosphatemia and hypocalcemia (3). When calcium was injected intravenously into such patients, the elevation of plasma concentration was very transient, and the rate at which the injected calcium escaped from the plasma appeared to be proportional to the degree of the pre-injection hypocalcemia and hyperphosphatemia, which, in turn, was roughly proportional to the degree of muscle damage. In order to maintain plasma calcium at a desired level, it was necessary to infuse calcium continuously. The purpose of the maintenance of a near-normal calcium level was to antagonize the toxic effects of hyperpotassemia, and in this respect prolonged infusions were quite effective; however, the desirability of the procedure was questioned because the fate of the infused calcium was unknown, and the quantities employed might be harmful if deposited in certain viscera.

At first consideration it might be assumed that the calcium which escaped from the plasma was deposited in bones. However, this would not explain the difference in the rate of disappearance of calcium from the plasma of patients with and without muscle injury, since the bones were similar in both. An alternate possibility is that some of the calcium was deposited in the damaged tissue, a phenomenon well recognized in chronic states but not known to occur acutely. It is to test this possibility that the present experiments are designed.

\footnotetext{
1 Previously published in abstract form (1).
}

\section{EXPERIMENTAL PROCEDURES AND METHODS}

Dogs 1 and 2 were given tracer doses of $\mathrm{Ca}^{45} \mathrm{Cl}_{2}$ intravenously on day zero, and plasma samples collected daily thereafter were analyzed for radioactivity, sodium, potassium, non-protein nitrogen, total protein, calcium, phosphorus, and $\mathrm{pH}$. On day 3 , with the animals under Nembutal ${ }^{1}$ anesthesia, a biopsy specimen was taken from the right forelimb, bilateral nephrectomy was performed, and the large muscles of the right hind limb were severely traumatized with a hammer, care being taken not to strike the femur. On day 6, biopsy specimens of approximately 20 grams were taken from the traumatized muscle of the right hind limb and the untraumatized muscle of a comparable area of the left hind limb.

Dogs 3,4 , and 5 were nephrectomized and traumatized in a similar way, and biopsies were taken on the third day. The muscle specimens were analyzed for calcium and fat only.

The procedure for dogs 6 and 7 was the same as for dogs 1 and 2 except that nephrectomy was not performed. The procedure for dog 8 was the same as for 6 and 7 except that the initial, normal biopsy was omitted and the biopsies of the hind limbs were performed on day 4 , 24 hours following injury.

Dogs 9 to 13 were not nephrectomized, the initial biopsies were omitted, and radioactive calcium was not given. Dog 9 received intravenously $1050 \mathrm{ml}$. of an aqueous solution containing $2.95 \mathrm{Gm} . \mathrm{NaH}_{2} \mathrm{PO}_{4}$ and $11.7 \mathrm{Gm}$. $\mathrm{Na}_{2} \mathrm{HPO}$, per liter (3.2 mgm. phosphorus per ml., $\mathrm{pH}$ 7.4) during the six hours following the trauma and preceding the biopsies. Dog 10 received $1200 \mathrm{ml}$. of this solution during the six hours following the trauma and an additional $1150 \mathrm{ml}$. over a six-hour period prior to biopsies the following day. Dog 11 received $600 \mathrm{ml}$. 0.4 molar $\mathrm{NaHCO}_{3}$ in water during the six hours following the trauma and preceding the biopsies. Dog 12 received 600 ml. 0.1 molar $\mathrm{HCl}$ in five per cent glucose during the six hours following the trauma and preceding the biopsies. Dog 13 received $300 \mu$ parathyroid extract (from a lot of known potency) intramuscularly immediately following trauma, and three doses of $200 \mu$ each at twohour intervals prior to biopsies six hours following trauma.

The tissues from the initial, normal biopsies were weighed, frozen, and saved to be processed with the specimens of traumatized and control muscle obtained on day 6. All specimens were minced and placed in a dry- 
ing oven at $87^{\circ} \mathrm{C}$. for 72 hours. Preliminary studies revealed that the loss of weight from minced tissues was minimal after 72 hours. Duplicate samples from each dried specimen were digested with nitric acid, heat, and perchloric acid. The digests were suspended in a carrier of normal plasma, and radioactivity was determined by use of a $Q$ gas flow counter for ten-minute periods. All results in tissue digests and plasma were corrected for self-absorption by comparison with a curve constructed using varying amounts of $\mathrm{Ca}^{\text {ss }}$ in normal plasma. The results were expressed as counts per minute per gram of wet, fat-free muscle and as counts per minute per milligram of calcium in plasma and wet, fat-free muscle. Fat was not removed from any muscle because of the likelihood that fluid would be lost from the edematous traumatized muscle, and the fat-free values reported were derived by calculation after the fat content was known from chemical analysis. The tissue concentrations were expressed per gram of wet weight in order that they might be related to wet weight of plasma. All chemical analyses were performed by methods previously reported from this laboratory (4) except fat, which was determined by a modification of the method of van de Kamer, Ten Bokkel Huinink, and Weyers (5). Nitrogen and fat content were determined from a separate sample of dried tissue; the other chemical determinations were performed on the acid digest.

\section{RESULTS}

The results for dogs 1 and 2 are shown in Table I. Chemical changes characteristic of the uremic state in dogs were apparent in each plasma sample following nephrectomy. Plasma specific activity (corrected counts per minute per milligram of total calcium) diminished daily as the injected $\mathrm{Ca}^{45}$ exchanged with the native calcium in the body pool. The normal muscle, obtained by biopsy of the forelimb prior to other procedures on day 3 , yielded chemical values which compare well with those cited by Sunderman and Boerner (6). The control muscle, which was undamaged but was removed on day 6 when the animals were uremic, yielded chemical values which deviated somewhat from normal but showed no large or consistent changes attributable to uremia. The specific activity of the control muscle was lower than that of the normal muscle removed three days previously because the plasma calcium with which it was exchanging had lower specific activity on day 6 . The traumatized muscles contained some 26 and 32 times more radioactivity per gram than the respective control muscles. The content of calcium, as measured chemically, was some 12 and 15 times greater in the traumatized than in the control muscles. The specific activity of the calcium was much greater in the traumatized muscle than in the plasma on day 6 , indicating that
TABLE II

Effect of trauma on water, fat, and calcium content of muscle *

\begin{tabular}{cccccc}
\hline \hline & Day & $\begin{array}{c}\text { Muscle } \\
\text { sample }\end{array}$ & $\begin{array}{c}\mathrm{H}_{2} \mathrm{O} \\
\%\end{array}$ & $\begin{array}{c}\text { Fat } \\
\%\end{array}$ & $\begin{array}{c}\text { Fat-free wet } \\
\text { muscle } \\
\text { Ca } \\
m g m . / G m .\end{array}$ \\
\hline Dog & 3 & Control & 70 & 10.5 & .090 \\
No. 3 & & Trauma & 73 & 9.5 & .798 \\
Dog & 3 & Control & 66 & 12.6 & .070 \\
No. 4 & & Trauma & 69 & 12.4 & .438 \\
Dog & 3 & Control & 71 & 8.4 & .057 \\
No. 5 & & Trauma & 78 & 6.4 & .654 \\
\hline
\end{tabular}

* Dogs 3,4 , and 5 were bilaterally nephrectomized and the large muscles of the right hind limbs were crushed on day zero. On day 3 muscle samples were obtained by biopsy from the area of trauma and a comparable area. of the left hind limb.

the muscle calcium was derived from plasma immediately following trauma, when the specific activity of plasma was higher, and suggesting that little exchange occurred between the calcium in the traumatized muscle and in plasma.

In dogs 3, 4, and 5 (Table II) the traumatized muscles removed 3 days following nephrectomy contained 9,6 , and 11 times as much calcium as the respective control muscles.

The results for dogs 6 and 7 are shown in Table III. These dogs were not nephrectomized but the other procedures were the same as for dogs 1 and 2. The degree of trauma administered was not regulated in any of the animals, and the change in $\mathrm{Na} / \mathrm{K}$ ratio is shown as one indication that the trauma was adequate to produce severe changes. In dogs 6 and 7 the plasma chemical changes, the daily diminution in plasma specific activity, and the increased $\mathrm{Na} / \mathrm{K}$ ratio in the traumatized muscle were similar to the changes in dogs 1 and 2. However, when compared with the control, the traumatized muscle contained only four times the radioactivity and twice the calcium. The specific activity was comparable with that of the plasma on day 4 or 5 , whereas the specific activity in the control muscle was comparable with that in plasma on day 6. The determinations of radioactivity in the muscle samples from $\operatorname{dog} 7$ were technically unsatisfactory and are not shown. In $\operatorname{dog} 8$ the traumatized muscle removed 24 hours following injury also revealed four times the radioactivity and twice the chemical calcium of the control (Table III). Again, the specific activity in the traumatized muscle compared best with that in plasma at the time of injury, whereas the spe- 


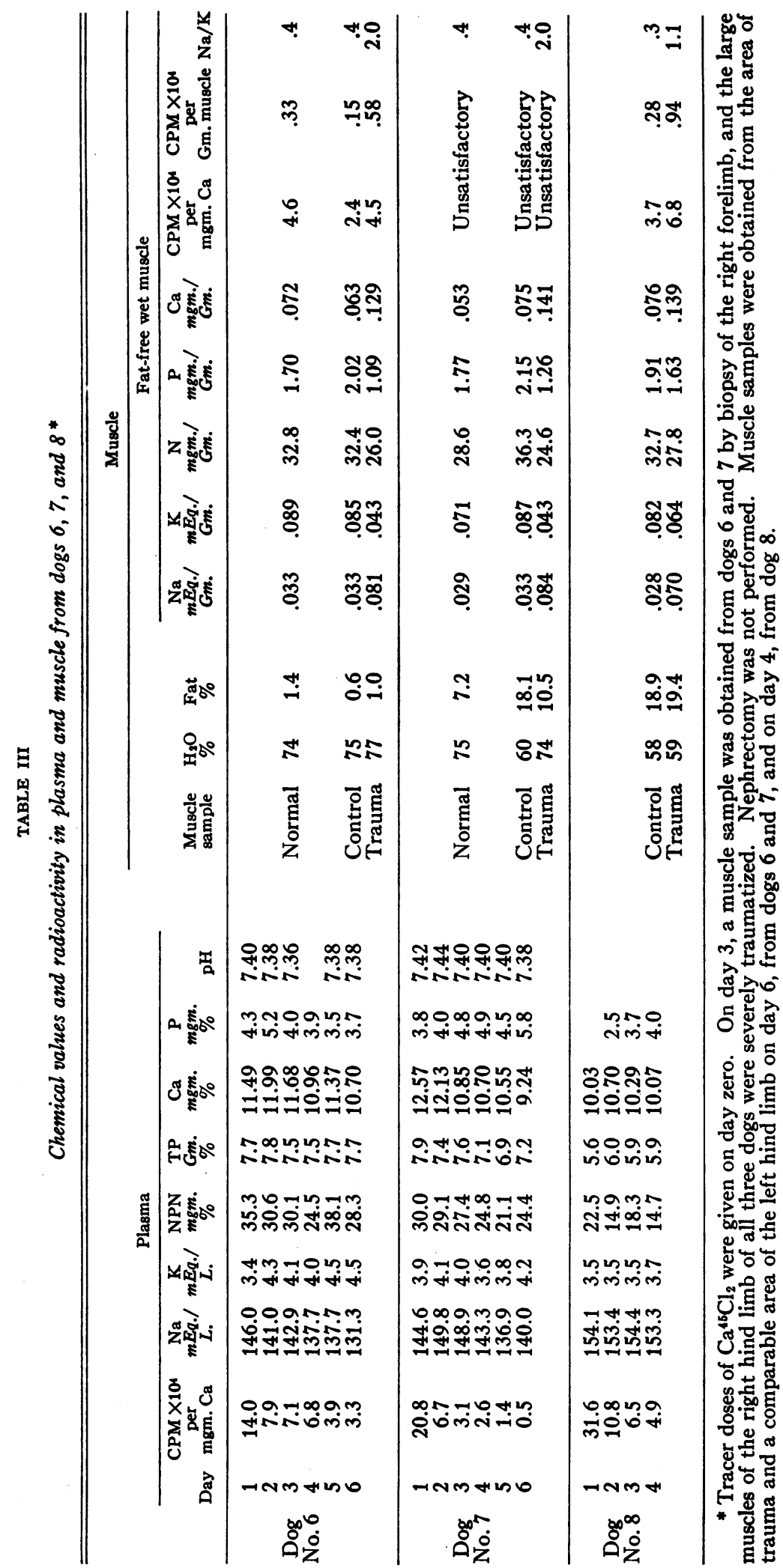


TABLE IV

Chemical values in plasma and muscles from dogs 9 and $10^{*}$

\begin{tabular}{|c|c|c|c|c|c|c|c|c|c|c|c|}
\hline & \multirow{2}{*}{\multicolumn{3}{|c|}{ Plasma }} & \multicolumn{8}{|c|}{ Muscle } \\
\hline & & & & \multirow[b]{2}{*}{$\begin{array}{l}\text { Muscle } \\
\text { sample }\end{array}$} & \multirow[b]{2}{*}{$\begin{array}{l}\mathrm{H}_{2} \mathrm{O} \\
\%\end{array}$} & \multirow[b]{2}{*}{$\begin{array}{l}\text { Fat }_{\%} \\
\text { at }\end{array}$} & \multicolumn{5}{|c|}{ Fat-free wet muscle } \\
\hline & $\begin{array}{c}\text { Day } \\
\text { Hour }\end{array}$ & $\underset{m g m . \%}{\mathrm{Ca}}$ & $\underset{m g m . \%}{\mathbf{P}}$ & & & & $\begin{array}{c}\mathrm{Na} \\
E_{q . / G m}\end{array}$ & $\underset{m E q . / G m .}{\mathrm{K}}$ & $\underset{m g m . / G m .}{\mathrm{P}}$ & $\underset{m g m . / G m .}{\mathrm{Ca}}$ & $\mathrm{Na} / \mathrm{K}$ \\
\hline \multirow{5}{*}{$\begin{array}{l}\text { Dog } \\
\text { No. } 9\end{array}$} & $\begin{array}{l}1 \\
2 \\
3\end{array}$ & $\begin{array}{l}11.15 \\
11.48\end{array}$ & $\begin{array}{l}5.4 \\
4.7\end{array}$ & & & & & & & & \\
\hline & 0900 & 8.81 & 19.7 & & & & & & & & \\
\hline & ${ }_{3}^{1100}$ & 7.97 & 15.5 & & & & & & & & \\
\hline & 1300 & 7.81 & 11.5 & & & & & & & & \\
\hline & $\begin{array}{c}3 \\
1500\end{array}$ & 7.97 & 9.9 & $\begin{array}{l}\text { Control } \\
\text { Trauma }\end{array}$ & $\begin{array}{l}61 \\
76\end{array}$ & $\begin{array}{r}13.6 \\
6.3\end{array}$ & $\begin{array}{l}.062 \\
.099\end{array}$ & $\begin{array}{l}.102 \\
.033\end{array}$ & $\begin{array}{l}2.25 \\
0.95\end{array}$ & $\begin{array}{l}.078 \\
.128\end{array}$ & $\begin{array}{r}.6 \\
3.0\end{array}$ \\
\hline \multirow{7}{*}{$\begin{array}{l}\text { Dog } \\
\text { No. } 10\end{array}$} & $\begin{array}{l}1 \\
2 \\
3\end{array}$ & $\begin{array}{l}10.87 \\
11.48\end{array}$ & $\begin{array}{l}4.9 \\
5.6\end{array}$ & & & & & & & & \\
\hline & $\begin{array}{c}0900 \\
3\end{array}$ & 9.66 & 18.5 & & & & & & & & \\
\hline & 1100 & 8.45 & 20.4 & & & & & & & & \\
\hline & $\begin{array}{c}1500 \\
4\end{array}$ & 7.73 & 15.7 & & & & & & & & \\
\hline & 0800 & 10.26 & 2.7 & & & & & & & & \\
\hline & 1100 & 9.42 & 11.4 & & & & & & & & \\
\hline & $\begin{array}{c}4 \\
1500\end{array}$ & 8.45 & 10.3 & $\begin{array}{l}\text { Control } \\
\text { Trauma }\end{array}$ & $\begin{array}{l}73 \\
73\end{array}$ & $\begin{array}{l}5.9 \\
8.0\end{array}$ & $\begin{array}{l}.033 \\
.079\end{array}$ & $\begin{array}{l}.086 \\
.046\end{array}$ & $\begin{array}{l}2.01 \\
1.24\end{array}$ & $\begin{array}{l}.062 \\
.106\end{array}$ & $\begin{array}{r}.4 \\
1.8\end{array}$ \\
\hline
\end{tabular}

* Dog 9 received a phosphate infusion over a six-hour period following trauma and preceding the biopsies. Dog 10 received a phosphate infusion over a six-hour period following trauma and an additional amount over the six-hour period preceding biopsies the following day.

cific activity in the control muscle was lower than that in plasma 24 hours following injury.

The twofold increase in calcium content of traumatized muscle was consistent in all the nonnephrectomized dogs. The infusion of phosphate for a 6-hour period in $\operatorname{dog} 9$ and for two 6-hour periods in dog 10 (Table IV), the infusion of alkali in dog 11 and acid in dog 12, and the administration of parathyroid hormone to dog 13 (Table V) did not alter the twofold increase in calcium deposition.

All specimens of traumatized muscle appeared edematous, and in eleven of the thirteen the water content, as estimated from the difference between wet and dry weight, was greater than that of the control specimens, but the magnitude of the increase was insufficient for contained plasma to produce the observed alterations in chemical concentration. The calcium concentration in traumatized muscle was greater than that in plasma, and any increase in the plasma contained in muscle could only serve to minimize the increase in muscle calcium. In order for the increase in sodium and the decrease in potassium content to have been the result of an influx of plasma, it would have been necessary for each gram of wet tissue to show an increase of water content averaging 33 per cent (range 0.19 to 0.44 , which in most instances would have replaced all the tissue solids), whereas the observed increase of water content averaged 4.7 per cent (range 0 to 0.14 ). The estimate of the water content of some specimens was unexpectedly low, but these were the specimens containing the greatest amount of fat, and the lower water content of fat may have accounted for the difference. Also, it is possible that the fat interfered with the loss of water during the drying period. These changes were found in both control and traumatized specimens, and the direction of the changes in chemical concentra- 


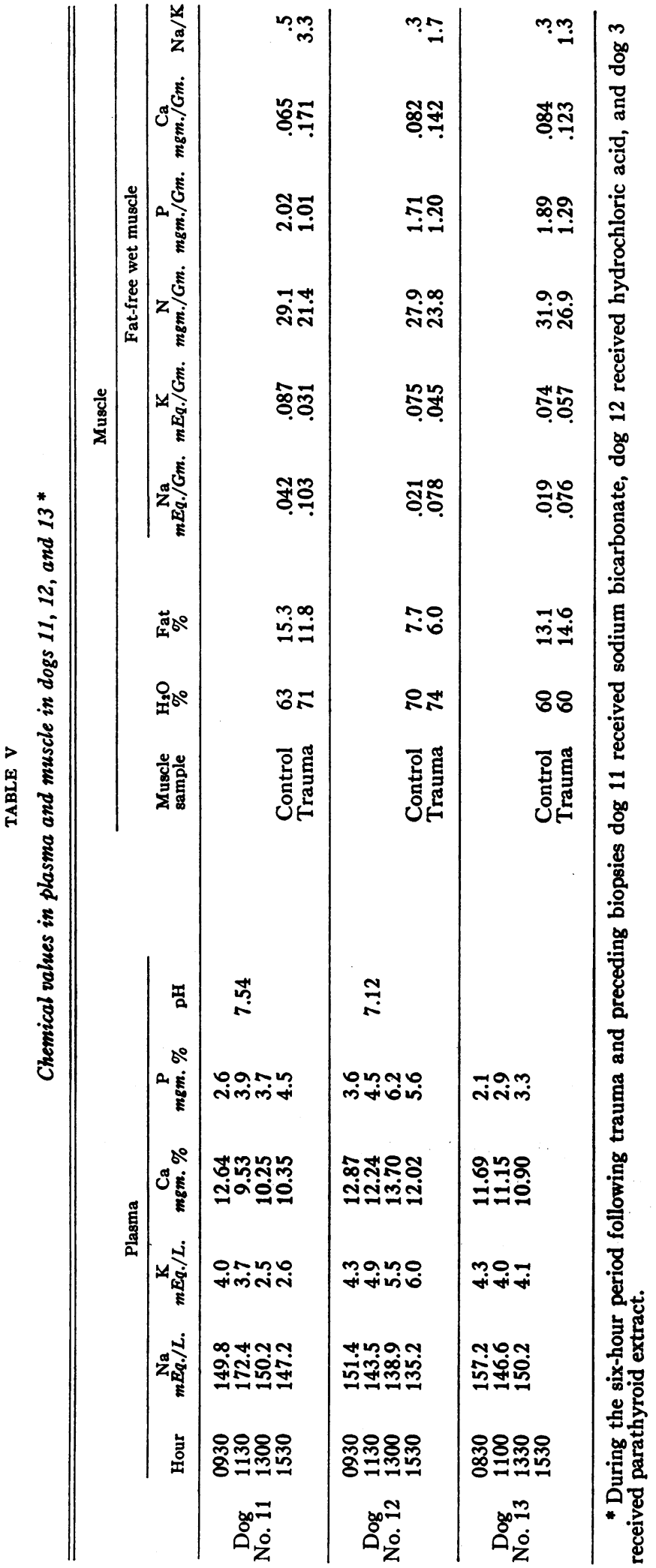


tion between pairs of specimens appeared to be unaffected. The fat content was increased in six and decreased in seven traumatized specimens and appeared to have no significance beyond chance selection of tissue specimens. All traumatized specimens analyzed contained increased sodium, decreased potassium and nitrogen, irrespective of water or fat content. With one exception, phosphate concentration was decreased in all traumatized specimens analyzed, including those from the animals which received phosphate infusions.

\section{DISCUSSION}

These experiments demonstrate that the propensity of damaged tissue to accumulate calcium, usually observed radiologically or histologically long after tissue damage, can be detected within a few hours after injury. The calcium in the damaged tissue, presumably bound to denatured protein, does not exchange freely with the calcium in the plasma. In the dog with uremia the quantity of calcium deposited in traumatized muscle is greatly increased, although the calcium content of undamaged muscle is not increased. The peculiarities associated with uremia which provoke these differences are unknown. The administration of phosphate, acid, alkali, and parathyroid extract did not influence the deposition of calcium in muscle under the conditions employed.

The finding of acute calcification of damaged muscle in the uremic dog is consistent with the observation that calcium escapes rapidly from the plasma of patients with post-traumatic uremia. Although the plasma concentration of calcium does not fall in the uremic dog as it does in the uremic man, the average quantity of calcium withdrawn from the plasma is of such a magnitude that one kilogram of damaged muscle would bind the calcium contained in $75 \mathrm{ml}$. of 10 per cent calcium gluconate $(0.67 \mathrm{Gm}$. calcium). The principal reason for the administration of calcium during post-traumatic uremia is to utilize its antagonistic action toward potassium; $75 \mathrm{ml}$. of 10 per cent calcium gluconate is a liberal and effective dose for this purpose, and one kilogram of damaged muscle is a conservative estimate of that present in some patients with such severe hyperpotassemia that it must be antagonized immediately to prevent cardiac death. Damaged muscle exaggerates both hyperpotassemia and hypocalcemia, since it releases potassium and accepts calcium. This does not suggest, however, that any direct exchange occurs between these substances of widely different properties. The damaged muscle which releases potassium also accepts sodium, and it is likely that these univalent cations do exchange directly.

The essential factors influencing calcium deposition are unknown, but in uremic man the escape of calcium from plasma is associated with an excess of plasma phosphate, an inorganic anion which may be derived from intracellular phosphorus. Hyperphosphatemia is more acute and extreme in uremic patients with muscle damage, and in the present dog experiments tissue phosphorus, determined as inorganic phosphate, is diminished in damaged muscle. The infusion of phosphate did not increase the deposition of calcium in the damaged dog muscle, although it did provoke hypocalcemia. Hyperphosphatemia and hypocalcemia appear, though more slowly, in anuric patients who have no demonstrable muscle damage, but the precipitation of calcium throughout the body, perhaps in the tissues which released the phosphate, has not been excluded.

Whatever the essential factors controlling calcium deposition may be, it appears possible that the mechanism involves an exchange with a divalent cation. Since it has been observed that plasma magnesium concentration is increased in anuric patients with hypocalcemia (7), a direct exchange between tissue magnesium and plasma calcium is not inconceivable.

\section{SUMMARY}

Experiments were performed in dogs to clarify the clinical observation that calcium which is infused into anuric patients escapes more rapidly from the plasma when damaged muscle is present. Using radioactive and standard chemical techniques it was found that damaged dog muscle doubled its calcium content in six hours; the quantity of calcium deposited in damaged muscle was increased by an average of more than tenfold in nephrectomized dogs; and the quantity of calcium contained in undamaged muscle was unaffected by nephrectomy. 
These findings are discussed in relation to the administration of calcium for the treatment of potassium intoxication. Speculation on the mechanism of calcification is offered.

\section{ACKNOWLEDGMENT}

The authors are indebted to Natalie L. Lawson and Betty M. Hackley for technical assistance.

\section{REFERENCES}

1. Meroney, W. H., Arney, G. K., Segar, W. E., and Balch, H. H., The acute calcification of damaged muscle with particular reference to acute posttraumatic renal insufficiency. J. Lab. \& Clin. Med., 1956, 48, 925.

2. Meroney, W. H., and Herndon, R. F., The management of acute renal insufficiency. J. A. M. A., 1954, $155,877$.

3. Meroney, W. H., The phosphorus to nonprotein nitrogen ratio in plasma as an index of muscle devitalization during oliguria. Surg., Gynec. \& Obst., 1955, 100, 309.

4. Analytical Procedures: Biochemistry Laboratory, Department of Metabolism, Army Medical Service Graduate School, Walter Reed Army Medical Center, Washington 12, D. C., 1955.

5. van de Kamer, J. H., Ten Bokkel Huinink, H., and Weyers, H. A., Rapid method for the determination of fat in feces. J. Biol. Chem., 1949, 177, 347.

6. Sunderman, F. W., and Boerner, F., Normal Values in Clinical Medicine. W. B. Saunders Company, Philadelphia, 1950.

7. Meroney, W. H., Unpublished data contained in Activities Report, Renal Insufficiency Center, Korea (filed at Walter Reed Army Institute of Research, Washington, D. C.). 